\title{
|||||||||||||||||||||||||||||||||||||||||||||||||||||||||||||||||||.
}

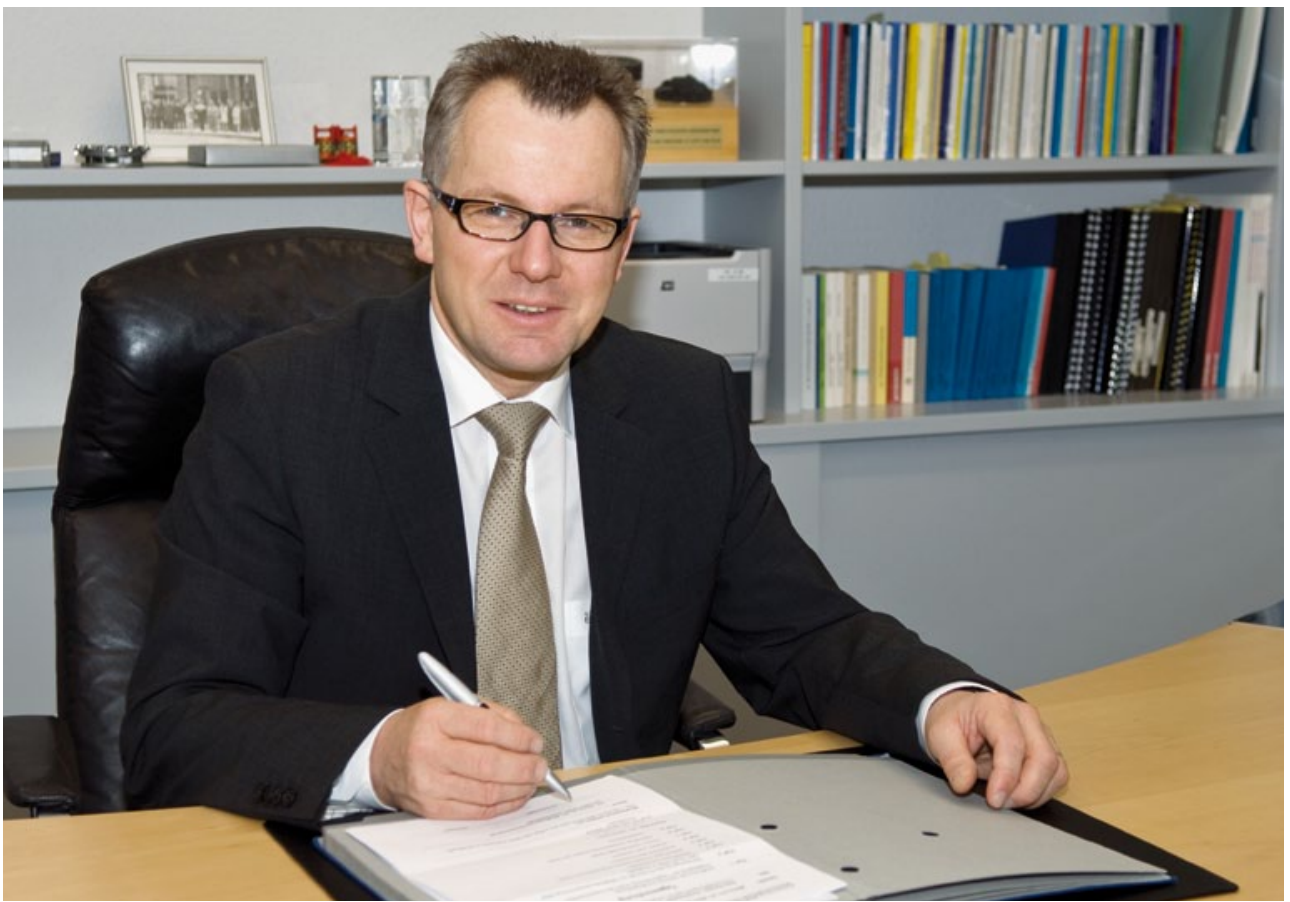

PROFESSOR DR.-ING. STEFAN PISCHINGER President \& CEO FEV GmbH

\section{STICKOXID- UND PARTIKELREDUKTION}

Die kontinuierliche Verbesserung der Luftqualität durch Absenkung der verbrennungstechnisch bedingten Abgasemissionen stellt seit langem einen zentralen Schwerpunkt der Entwicklungsanstrengungen dar, durch die in den vergangenen Jahrzehnten Reduzierungen von über $90 \%$ für alle Schadstoffkomponenten erreicht wurden.

Die strengsten Emissionsstandards belegen, dass einerseits mit modernen Motoren extrem niedrige Abgasemissionswerte erreicht werden können, zum anderen die Grenze des sinnvoll Machbaren mit den heute verfügbaren Technologien nahezu erreicht ist. Das gilt insbesondere vor dem Hintergrund, dass zunehmend neben den klassischen Schadstoffen die $\mathrm{CO}_{2}$-Emissionen in den Fokus geraten. Neben einer weltweit intensivierten Konzentration auf die Reduzierung der klimabeeinflussenden $\mathrm{CO}_{2}$-Emissionen fokussiert sich die Emissionsminderung in Zukunft daher weitgehend auf eine verbesserte Abbildung des realen Motorbetriebs im gesetzlichen Prüfzyklus durch Einbeziehung weiterer Betriebs- und Temperaturbereiche sowie einer weltweiten Harmonisierung der aktuell unterschiedlichen Prüfzyklen. Zusätzlich gilt es, die teilweise sehr hohen Kosten des Abgasnachbehandlungssystems zu senken.

Der stöchiometrisch betriebene Ottomotor hält mithilfe der Dreiwege-Katalysatortechnik alle für die Zukunft beschlossenen gasförmigen Emissionsgrenzen ein. Selbst für den mager betriebenen Ottomotor steht mit dem $\mathrm{NO}_{\mathrm{x}}$-Speicherkatalysator eine zuverlässige, wenn auch teure, Abgasreinigungstechnolo- gie zur Verfügung. Die beim direkteinspritzenden Ottomotor zusätzlich limitierte Partikelmasse sowie die Partikelanzahl lassen sich durch optimiertes Einspritzequipment sowie präzise Einspritzsteuerung sowohl beim stöchiometrisch als auch mager betriebenen Ottomotor zuverlässig beherrschen. Für den Dieselmotor erfordert dies noch erheblichen Entwicklungsaufwand. Innermotorisch wird durch eine weitere Verfeinerung der wesentlichen Technologieelemente Ladungsfüllung und -bewegung, Hochdruckeinspritzung, Aufladung und Abgasrückführung und entsprechender Brennraumoptimierung mit verbessertem Homogenisierungsgrad eine schrittweise Absenkung des Rohemissionsniveaus verfolgt, unter Beibehaltung eines hohen Prozesswirkungsgrads. Im Bereich der nachmotorischen Abgasminderung erfolgen weitere Verbesserungen im Bereich der katalytischen Beschichtung hinsichtlich Anspringverhalten und verbesserter Umsatzraten bei niedrigen Abgastemperaturen sowie integrierter Gesamtlösungen (zum Beispiel Filter-SCR), erweiterter Systemrobustheit und verbessertem Alterungsverhalten.

Zur frühzeitigen Identifikation eines wirkungsvollen, kostengünstigen sowie robusten Gesamtpakets sind modernste, abgesicherte Simulationswerkzeuge und integrierte, leistungsfähige Werkzeugketten unabdingbar.

In Verbindung mit der zunehmenden Hybridisierung werden die Verbrennungsmotoren in der nächsten Dekade damit über eine weitere, massive Verminderung der Abgasemission einen 